University of South Carolina

Scholar Commons

\title{
Estimation of Electrode Kinetic Parameters of the Lithium/Thionyl Chloride Cell Using a Mathematical Model
}

\section{T. I. Evans}

Texas A \& M University - College Station

Ralph E. White

University of South Carolina - Columbia, white@cec.sc.edu

Follow this and additional works at: https://scholarcommons.sc.edu/eche_facpub

Part of the Chemical Engineering Commons

\section{Publication Info}

Journal of the Electrochemical Society, 1989, pages 2798-2805.

(c) The Electrochemical Society, Inc. 1989. All rights reserved. Except as provided under U.S. copyright law, this work may not be reproduced, resold, distributed, or modified without the express permission of The Electrochemical Society (ECS). The archival version of this work was published in the Journal of the Electrochemical Society.

http://www.electrochem.org/

DOI: $10.1149 / 1.2096289$

http://dx.doi.org/10.1149/1.2096289

This Article is brought to you by the Chemical Engineering, Department of at Scholar Commons. It has been accepted for inclusion in Faculty Publications by an authorized administrator of Scholar Commons. For more information, please contact digres@mailbox.sc.edu. 


\title{
Estimation of Electrode Kinetic Parameters of the Lithium/ Thionyl Chloride Cell Using a Mathematical Model
}

\author{
T. I. Evans' ${ }^{\text {and R. E. White* }}$
}

Department of Chemical Engineering, Texas A\&M University, College Station, Texas 77843

\begin{abstract}
A one-dimensional mathematical model for the lithium/thionyl chloride primary cell is used in conjunction with a parameter estimation technique, in order to estimate the electrode kinetic parameters of this electrochemical system. The electrode kinetic parameters include the anodic transfer coefficient and exchange current density of the lithium oxidation, $\alpha_{\mathrm{a}, 1}$ and $i_{\mathrm{o}, 1 \text {.ref; }}$ the cathodic transfer coefficient and the effective exchange current density of the thionyl chloride re-

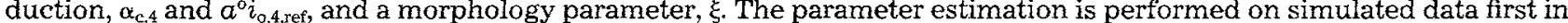
order to gain confidence in the method. Data reported in the literature for a high-rate discharge of an experimental lithium/thionyl chloride cell is used for an analysis.
\end{abstract}

This work is part of an ongoing effort to characterize the lithium/thionyl chloride ( $\left.\mathrm{Li} / \mathrm{SOCl}_{2}\right)$ cell in order to understand better the physical system and improve its safety and performance. The $\mathrm{Li} / \mathrm{SOCl}_{2}$ cell is an attractive primary energy source because of its high energy density $(1,2)$. A description of the $\mathrm{Li} / \mathrm{SOCl}_{2}$ cell along with the safety hazards it exhibits is discussed elsewhere (2).

A detailed mathematical model of this battery has been presented (3). The model is used here in conjunction with a parameter estimation technique in order to establish a means to estimate the electrode kinetic parameters, which aid in describing the physical system. The assumptions and governing equations used in the model are given elsewhere (3). A description of the model parameters, the sensitivity of the model predictions to changes in these parameters, and estimates of these parameters, based on available experimental data (4), are presented next.

\section{Model Parameters}

The model (3) includes several reactions: the oxidation of lithium at the anode

$$
\mathrm{Li} \rightarrow \mathrm{Li}^{+}+e^{-}
$$

the reduction of $\mathrm{SOCl}_{2}$ at the cathode

$$
2 \mathrm{SOCl}_{2}+4 e^{-} \rightarrow 4 \mathrm{Cl}^{-}+\mathrm{SO}_{2}+\mathrm{S}
$$

and the precipitation of $\mathrm{LiCl}$ on the pore surfaces of the cathode during discharge by the following reaction

$$
\mathrm{Li}^{+}+\mathrm{Cl}^{-} \rightleftharpoons \mathrm{LiCl}(\mathrm{s})
$$

Due to the low solubility of $\mathrm{LiCl}$ in the $\mathrm{SOCl}_{2}+\mathrm{LiAlCl}_{4}$ $\operatorname{mix}(5)$, reaction [3] is assumed to occur completely and instantaneously. Thus, reactions [2] and [3] can be combined to yield one overall reaction representing the processes occurring within the porous cathode (3)

$$
4 \mathrm{Li}^{+}+4 e^{-}+2 \mathrm{SOCl}_{2} \rightarrow 4 \mathrm{LiCl}+\mathrm{SO}_{2}+\mathrm{S}
$$

Four species are included in the model: $\mathrm{Li}^{+}, \mathrm{AlCl}_{4}{ }^{-}, \mathrm{SOCl}_{2}$, and $\mathrm{LiCl}$

The electrochemical reaction rates, $i_{\mathrm{k}}$, depend upon the local concentrations of the chemical species, the potential driving force for reaction, and the temperature. The Butler-Volmer polarization equation for a flat plate electrode $(6,7)$ is used in the model $(3)$

\footnotetext{
*Electrochemical Society Active Member.

${ }^{1}$ Present address: E. I. du Pont de Nemours \& Co., Marshall Laboratory, Philadelphia, PA 19146
}

$$
\begin{aligned}
i_{\mathrm{k}}=i_{\mathrm{o}, \mathrm{k}, \mathrm{ref}}\left[\prod_{\mathrm{i}}\left(\frac{c_{\mathrm{i}}}{c_{\mathrm{i}, \mathrm{ref}}}\right)^{\mathrm{p}_{\mathrm{i}, \mathrm{k}}}\right. & \exp \left(\frac{\alpha_{\mathrm{a}, \mathrm{k}} \mathbf{F}}{R T} \eta_{\mathrm{k}}\right) \\
& \left.-\prod_{\mathrm{i}}\left(\frac{c_{\mathrm{i}}}{c_{\mathrm{i}, \mathrm{ref}}}\right)^{\mathrm{q}_{\mathrm{i}, \mathrm{k}}} \exp \left(-\frac{\alpha_{\mathrm{c}, \mathrm{k}} \mathbf{F}}{R T} \eta_{\mathrm{k}}\right)\right]
\end{aligned}
$$

where

$$
\eta_{\mathrm{k}}=\Phi_{\mathrm{s}}-\Phi_{\mathrm{o}}-U_{\mathrm{k}, \mathrm{ref}}
$$

In Eq. [6], $\eta_{\mathrm{k}}$ is the potential driving force for electrochemical reaction $k$. The electrode kinetic parameters $i_{\mathrm{o}, \mathrm{k}, \mathrm{ref}}, \alpha_{\mathrm{a}, \mathrm{k}}$, and $\alpha_{c, k}$ are the exchange current density, anodic transfer coefficient, and cathodic transfer coefficient for reaction $k$, respectively. These electrode kinetic parameters characterize the electrochemical reaction via Eq. [5] and are the parameters that are sought in this work. Note that the transfer coefficients for a given reaction sum to the total number of electrons involved in that reaction

$$
\alpha_{\mathrm{a}, \mathrm{k}}+\alpha_{\mathrm{c}, \mathrm{k}}=n_{\mathrm{k}}
$$

Hence, only one of the transfer coefficients need be estimated and the remaining one can be obtained from Eq. [7].

Equation [5] must be modified slightly in order to describe the rate of reaction [4] in the porous carbon cathode. The rate of reaction [4] must be expressed per unit volume of porous electrode. This change is accomplished by premultiplying Eq. [5] by the available active surface area per unit volume of electrode, $a$. The variable $a$ changes as the $\mathrm{LiCl}$ precipitates on the pore walls, according to reaction $[4]$, and can be described by $(8,9)$

$$
a=a^{\circ}\left[1-\left(\frac{\epsilon^{\circ}-\epsilon}{\epsilon^{\circ}}\right)^{\xi}\right]
$$

where $\xi$ is an experimentally determined parameter used to describe the morphology of the precipitate. In writing Eq. [8] it is assumed that all the $\mathrm{LiCl}$ produced from reaction [4] precipitates instantaneously and passivates the surface it covers. Large values of $\xi$ indicate needle-shaped deposits whereas small values represent flat deposits (9). Premultiplying Eq. [5] by Eq. [8] yields the following equation for the rate of reaction [4] per unit volume of porous electrode

$$
\begin{aligned}
& j=a^{\mathrm{o}}\left[1-\left(\frac{\epsilon^{\mathrm{o}}-\epsilon}{\epsilon^{\mathrm{o}}}\right)^{\xi}\right] i_{0,4, \mathrm{ref}}\left[\prod_{\mathrm{i}}\left(\frac{c_{\mathrm{i}}}{c_{\mathrm{i}, \mathrm{ref}}}\right)^{\mathrm{p}_{\mathrm{i}, 4}} \exp \left(\frac{\boldsymbol{\alpha}_{\mathrm{a}, \mathrm{k}} \mathbf{F}}{R T} \eta_{4}\right)\right. \\
& \left.-\prod_{\mathrm{j}}\left(\frac{c_{\mathrm{i}}}{c_{\mathrm{i}, \mathrm{ref}}}\right)^{\mathrm{q}_{\mathrm{i}, 4}} \exp \left(-\frac{\alpha_{\mathrm{c}, \mathrm{k}} \mathbf{F}}{R T} \eta_{4}\right)\right]
\end{aligned}
$$


The effective exchange current density for reaction [4] is the product $a^{\circ} i_{0,4, \mathrm{ref}}$. In all, nine electrode kinetic parameters, $i_{0.1, \text { ref }}, \alpha_{\mathrm{a} .1}, \alpha_{\mathrm{c} .1}, \alpha^{0} i_{0,4, \mathrm{ref},}, \alpha_{\mathrm{a} .4}, \alpha_{\mathrm{c}, 4}, q_{+, 1}, q_{+, 4}$, and $q_{0,4}$, and one morphology parameter, $\xi$, are used (3); two of the transfer coefficients, $\alpha_{c .1}$ and $\alpha_{a, 4}$, are not independent quantities because they can be calculated from $\alpha_{a, 1}$ and $\alpha_{c, 4}$ via Eq. [7].

Several parameters are used in the model (3) to describe the species transport. The diffusion coefficient, $D$, is used to characterize the diffusion of the salt $\left(\mathrm{LiAlCl}_{4}\right)$ in the solvent $\left(\mathrm{SOCl}_{2}\right)$ due to concentration gradients in the cell. In the model (3), the diffusion coefficient is calculated using the following expression

$$
D=\beta_{6} \exp \left(\beta_{5} / T\right)
$$

where $\beta_{5}$ and $\beta_{6}$ are constants. The transference number of charged species $i, t_{1}$, is used to describe the migration of species $i$ in the cell due to the electric field. Two charged species are considered in the model, $\mathrm{Li}^{+}$and $\mathrm{AlCl}_{4}{ }^{-}$; therefore two transference numbers are used, $t_{+}$and $t_{-}$. Only one transference number is independent because they must sum to one

$$
t_{+} \mathbf{\varpi}+t_{-}=1
$$

When no concentration gradients exist, the transference number of a particular species represents the fraction of the current carried by that species (10). When concentration gradients do exist, however, the transference number loses this physical interpretation but can be thought of as a weighting factor which determines the importance of the migration term in the flux expression.

In order to use the model (3) to predict cell performance for various cell designs, investigate scale-up, and optimize a $\mathrm{Li} / \mathrm{SOCl}_{2}$ cell, estimates of the electrode kinetic parameters are needed. Given experimental data for a particular $\mathrm{Li} / \mathrm{SOCl}_{2}$ cell or half-cell, along with the complete cell specifications, it should be possible to use a parameter estimation technique to obtain these electrode kinetic parameters. A sensitivity analysis is conducted first to determine the relative importance of each parameter, followed by parameter estimation using simulated data to gain confidence in the procedure, and finally an experimental discharge curve is used to find the $\mathrm{SOCl}_{2}$ electrode kinetic parameters.

\section{Sensitivity Analysis}

It is important to determine the sensitivity of the model predictions to changes in the electrode kinetic parameters. If the model predictions are relatively insensitive to one or more of the parameters then a fairly wide range of values for these insensitive parameters could be used without significantly affecting the predictions of the model. Such parameters need to be identified so that they can be discarded from the parameter estimation procedure. Also, it is often the case that the more parameters that are estimated, the more uncertain are the estimates due to interaction between the parameters, poor scaling, and round-off error (11). In addition to the identification of insensitive parameters, the operating conditions or situations under which the sensitivity to given parameters is a maximum can be determined.

The sensitivity of the model predictions to changes in parameters is determined here by monitoring the change in cell voltage. While holding all other parameters constant, the parameter of interest is perturbed slightly and the resulting change in cell voltage is noted. A sensitivity coefficient is calculated as follows

$$
S C_{\mathrm{i}}=\frac{\sum^{\mathrm{n}_{\mathrm{j}=1}}\left|\triangle E\left(t_{\mathrm{j}}\right)\right|}{n\left|\triangle P_{\mathrm{j}}\right|}
$$

where

$$
\begin{gathered}
\Delta E\left(t_{\mathrm{j}}\right)=E\left(t_{\mathrm{j}}\right)-E^{*}\left(t_{\mathrm{j}}\right) \\
\Delta P_{\mathrm{i}}=\frac{P_{\mathrm{i}}-P^{*_{\mathrm{j}}}}{P^{*}{ }_{\mathrm{i}}}
\end{gathered}
$$

$P_{\mathrm{i}}$ and $P^{*}$ are the perturbed value of electrode kinetic parameter $i$ and the reference value of parameter $i$, respectively. $E\left(t_{\mathrm{j}}\right)$ is the value of the cell voltage at time $t_{\mathrm{j}}$ when using $P_{i}$, and $E^{*}\left(t_{j}\right)$ is the value of the cell voltage at time $t_{j}$ when using $P^{*}$. In Eq. [12], $n$ is the number of times over which the voltages are compared.

Many factors come into play when calculating the sensitivity coefficients. The influence of a particular parameter on cell voltage varies depending on the discharge rate, depth of discharge, and temperature. For example, the exchange current densities, $i_{0,1, \text { ref }}$ and $a^{\circ} i_{0,4 \text {,ref }}$, strongly influence the initial drop in cell voltage from the open-circuit potential (12). On the other hand, the powers on the concentration terms, $q_{+, 1}, q_{+, 4}$, and $q_{o, 4}$, have more influence later in the discharge when concentrations change more drastically due to localized reactant depletion. Therefore, the value of $n$ in Eq. [12] is chosen so that approximately $80 \%$ of the discharge is included in the analysis.

The results of the sensitivity analysis are shown in Fig. 1 and 2. Figure 1 shows the sensitivity of the cell voltage to the electrode kinetic parameters describing the lithium oxidation, reaction [1], over a range of discharge rates. Figure 2 is an analogous plot for reaction [4]. The most influential parameter by far is the lithium oxidation transfer coefficient $\alpha_{a, 1}$. This is to be expected because $\alpha_{a, 1}$ is in the exponential portion of Eq. [5]. The lithium oxidation exchange current density, $i_{0,1 \text { ref }}$ and $\mathrm{SOCl}_{2}$ reduction transfer coefficient, $\alpha_{c .4}$, are next, followed by the effective $\mathrm{SOCl}_{2}$ exchange current density, $\alpha^{\circ} i_{0,4 \text { ref }}$ and the morphology parameter, $\xi$. The electrode kinetic parameters describing the $\mathrm{SOCl}_{2}$ reduction display less influence than those describing the lithium oxidation. This could be due to the fact that the lithium oxidation occurs at the surface of a flat-plate electrode (a boundary condition in the model) whereas the $\mathrm{SOCl}_{2}$ reduction occurs throughout the porous structure of the cathode (a pseudohomogeneous region in the model) The overall influence of the $\mathrm{SOCl}_{2}$ reduction electrode kinetic parameters is, in effect, decreased because the change in voltage is distributed over the thickness of the cathode as opposed to the change occurring all at one point. The exponents on the power terms, $q_{+, 1}, q_{+, 4}$, and $q_{0,4}$,

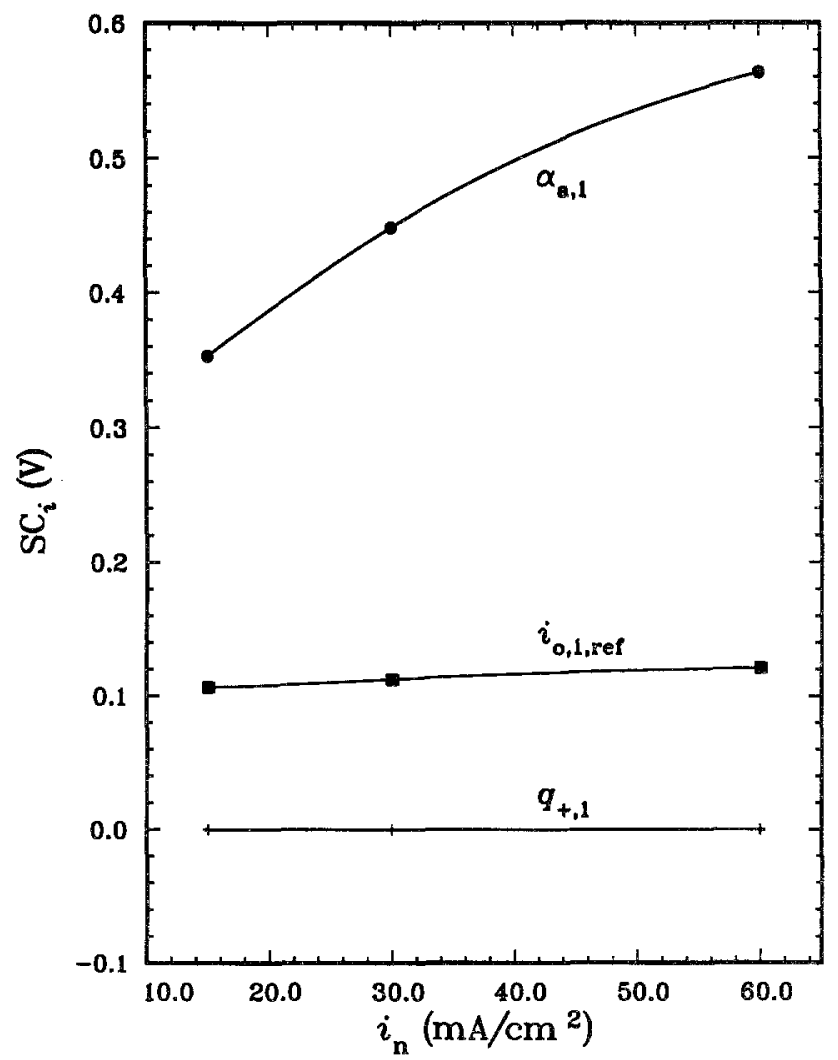

Fig. 1. Sensitivity of the predicted cell voltage to changes in the electrode kinetic parameters characterizing the lithium oxidation reaction [1]. 


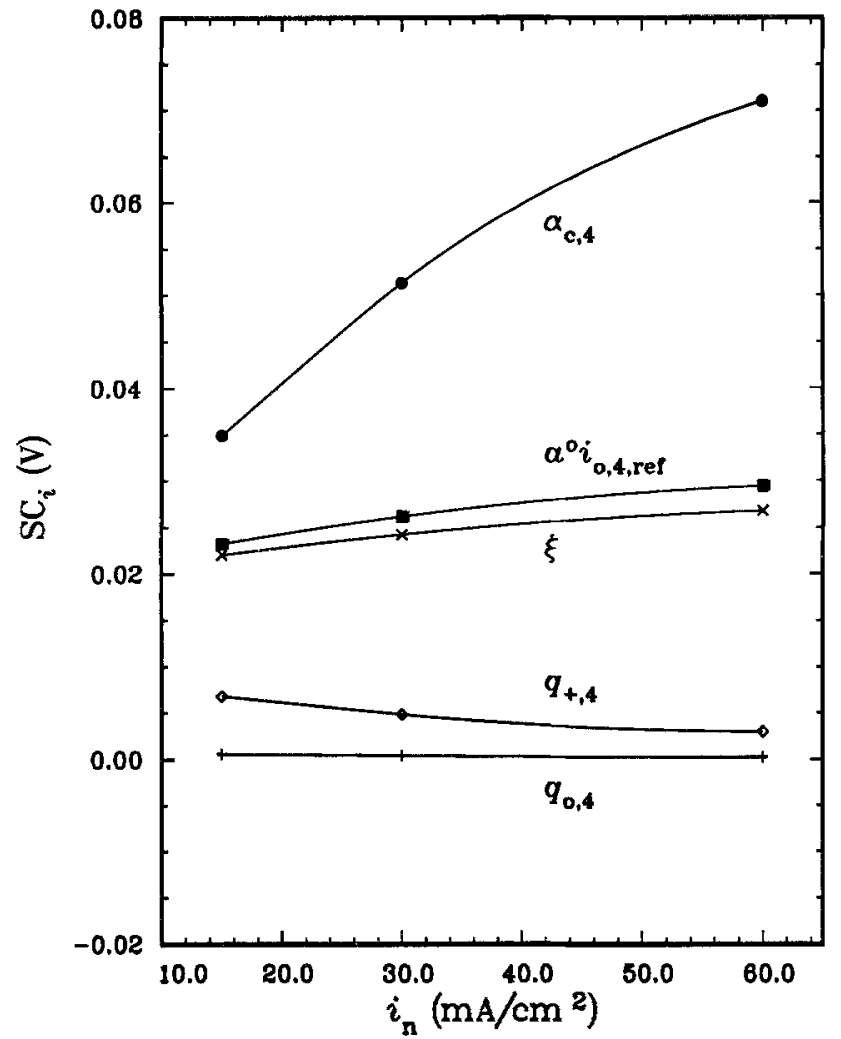

Fig. 2. Sensitivity of the predicted cell voltage to changes in the electrode kinetic parameters characterizing the $\mathrm{SOCl}_{2}$ reduction, reaction [4].

show little influence at the discharge rates investigated. They are discarded from most of the parameter estimation work presented next; they are set to the corresponding stoichiometric value as is often done.

The sensitivity of model predictions to changes in two of the transport parameters, $t_{\mathrm{i}}$ and $\beta_{6}$, was briefly investigated as shown in Fig. 3. At high current densities, the transference number shows substantial influence and the effects of diffusion become important. However, the sensitivity to these parameters is reduced as the current is reduced because the electrochemical reaction rates become controlling. This result suggests that a parameter estimation procedure aimed at finding the electrode kinetic parameters should be performed with low-rate data so that species transport will not interfere with the accuracy of the estimates.

\section{Parameter Estimation}

Klinedinst and Domeniconi (4) investigated the performance of a single $\mathrm{Li} / \mathrm{SOCl}_{2}$ cell with various carbon electrode thicknesses and operated over various discharge rates. Their experimental test cell has some features which make it attractive for obtaining experimental cell voltages for comparison with the model predictions here. The single cell, corresponding to the single cell model (3), is immersed in excess electrolyte and hence the cell temperature remains nearly constant throughout the discharge. The electrolyte is introduced into the test cell shortly before the beginning of the test (approximately $10 \mathrm{~min}$ before), suggesting that little or no secondary $\mathrm{LiCl}$ film is present on the Li electrode. Also, the anode, separator, and cathode are pressed together with a weight so that no reservoir exists between the separator and cathode.

The cell model (3) was changed to simulate this test cell for the parameter estimation. The film and reservoir regions were eliminated from the model by setting the film porosity equal to the separator porosity, removing the reservoir calculations from the model, and modifying slightly the boundary conditions at the reservoir/porous electrode interface to be those for the separator/porous electrode interface. The model inputs for simulating the test cell of Klinedinst and Domeniconi are listed in Table I.

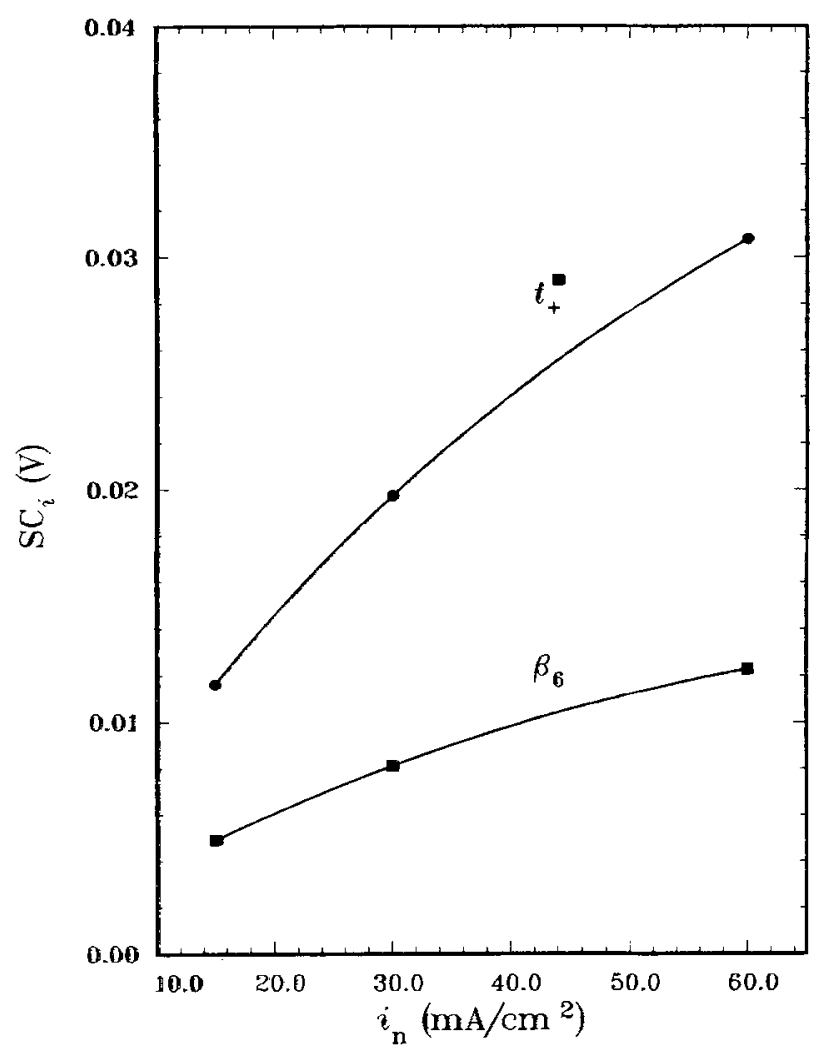

Fig. 3. Sensitivity of the predicted cell voltage to changes in the transport parameters characterizing migration $\left(t_{+}\right)$and diffusion $\left(\beta_{6}\right)$ of the electrolyte.

Initially, simulated data for both a $1 \mathrm{~mA} / \mathrm{cm}^{2}$ and a $31 \mathrm{~mA} / \mathrm{cm}^{2}$ discharge were used for the parameter estimation in order to gain confidence in the procedure and guide future experimentation. Experimental data for a $31 \mathrm{~mA} / \mathrm{cm}^{2}$ discharge were used to estimate the $\mathrm{SOCl}_{2}$ reduction electrode kinetic parameters for this high-rate discharge.

Reformulation of the Butler-Volmer equation.-To reduce the interaction between parameters in the least squares procedure, it is sometimes necessary to reformulate the model equations. Parameter interaction is evident when small changes in the parameters produce similar changes in the objective function. Interaction often occurs

Table I. Model inputs used to simulate a $1 \mathrm{~mA} / \mathrm{cm}^{2}$ discharge of an experimental test cell (4)

Numerical parameters:

Total number of node points

Maximum time step ( $\triangle t_{\text {max }}$ )

Physical properties and initial conditions:

Cell temperature $(T)$

Initial electrolyte concentration ( $c_{\text {init }}$ )

Reference electrolyte concentration $\left(c_{\text {ref }}\right)$

Transference number $\left(t_{+}\right)$

All other values as in Tables I and II of Ref. (3)

Cell dimensions:

Thickness of cathode $\left(S_{\mathrm{pe}}\right)$

Initial porosity of cathode $\left(\epsilon^{\circ}\right)$

Thickness of separator $\left(S_{s}\right)$

Porosity of separator $\left(\epsilon_{\mathrm{s}}\right)$

Thickness of reservoir $\left(S_{\mathrm{r}}\right)$

Thickness of film $\left(S_{\mathrm{f}}\right)$

Lithium oxidation electro-kinetic parameters:

$i_{\text {o.l. ref }}$

$\alpha_{\text {c.1 } 1}\left(=1-\alpha_{\text {a.1 }}\right)$

$q+1$

$=21$

$=2000 \mathrm{~s}$

$=25^{\circ} \mathrm{C}$

$=1.8 \mathrm{M}$

$=1.8 \mathrm{M}$
$=0.9$

$\mathrm{SOCl}_{2}$ reduction electro-kinetic parameters:

$a^{\circ} i_{0,4 \text {,ref }}$

$\alpha_{e, 4}$

$\alpha_{\mathrm{a}, 4}\left(=2-\alpha_{\mathrm{c}, 4}\right)$

$\stackrel{\xi}{q}_{+, 4}$

$q_{0,4}$
$=0.05 \mathrm{~cm}$

$=0.845$

$=0.0127 \mathrm{~cm}$

$=0.7$

$=0 \mathrm{~cm}$

$=0 \mathrm{~cm}$

$=0.002 \mathrm{~mA} / \mathrm{cm}^{2}$

$=0.5$

$=\quad 0.5$

$=0.005 \mathrm{~mA} / \mathrm{cm}^{3}$

$=0.0$
$=\quad 1.0$

$=1.0$

$=0.05$

$=1.0$
$=\quad 0.5$ 
when the parameters appear as a product somewhere in the governing equation. Interaction can be reduced if the equation is rewritten so that the parameters appear in separate terms.

As shown in Eq. [9], the electrode kinetic parameters in the Butler-Volmer equation appear in product terms as opposed to separate terms. The Butler-Volmer equation can be rearranged by first taking the natural logarithm and then taking the exponent of the various terms (12). For the parameter estimation used here, Eq. [9] is written as follows

$j=\exp \left[f_{1}+f_{2}\right]-\exp \left[f_{1}+f_{3}+f_{4}+f_{5}\right]-\exp \left[f_{1}+f_{2}+f_{6}\right]$

$$
+\exp \left[f_{1}+f_{3}+f_{4}+f_{5}+f_{6}\right] \quad[15]
$$

where

$$
\begin{gathered}
f_{1}=\ln \left(\mathrm{a}^{\circ} i_{0,4, \mathrm{ref}}\right) \\
f_{2}=\frac{\alpha_{\mathrm{a}, 4} \mathbf{F}}{R T}\left(\Phi_{1}-\Phi_{2}-U_{4, \mathrm{ref}}\right) \\
f_{3}=q_{+, 4} \ln \left(\frac{\mathrm{c}}{c_{\mathrm{ref}}}\right) \\
f_{4}=q_{0,4} \ln \left(\frac{c_{\mathrm{o}}}{c_{0, \mathrm{ref}}}\right) \\
f_{5}=-\frac{\alpha_{\mathrm{c}, 4} \mathbf{F}}{R T}\left(\Phi_{1}-\Phi_{2}-U_{4, \mathrm{ref}}\right) \\
f_{6}=\xi \ln \left(\frac{\epsilon^{\mathrm{o}}-\epsilon}{\epsilon^{\mathrm{o}}}\right)
\end{gathered}
$$

Equation [5] for reaction [1] is rewritten in a similar fashion. As a result of this reformulation, the parameters used in the parameter estimation procedure are $\ln \left(\alpha^{0} i_{0,4, \mathrm{ref}}\right), \alpha_{c, 4}, \xi$, $\alpha_{\mathbf{a}, 1}$, and $\ln \left(i_{\mathrm{o}, 1, \mathrm{ref}}\right)$.

Introduction of noise into simulated data.-In order to test the ability of the parameter estimation procedure to predict the model parameters within reasonable accuracy, random noise was added to the simulated data. A random number generator from the IMSL library (13) was used to generate a normally distributed number, $\phi$, with mean zero and variance one (i.e., $\sim \mathrm{N}(0,1))$. The noise was added to the predicted value of the cell potential at time $t_{j}, E\left(t_{j}\right)$, as follows

$$
E\left(t_{\mathrm{j}}\right)_{\text {with noise }}=E\left(t_{\mathrm{j}}\right)+\phi Z
$$

where $Z$ is the average level of noise presumably inherent in the measurement of the cell voltage. Three levels of $Z$ were investigated here, $0.5 \mathrm{mV}, 1 \mathrm{mV}$, and $2 \mathrm{mV}$. It is realistic to assume that the experimental measurements of the cell voltage would be accurate to within $2.0 \mathrm{mV}$.

Calculation of confidence intervals for parameter estimates.-An estimate of a parameter has little meaning unless it is accompanied by some approximation of the possible error it possesses. Here, confidence intervals for the parameter estimates can be estimated by using the following formula (14)

$$
P_{\mathrm{i}}=\hat{P}_{\mathrm{i}} \pm t_{(1-\gamma / 2),(\mathrm{n}-\mathrm{m})} s_{\mathrm{Pi}}
$$

In Eq. [23], $\hat{P}_{\mathrm{i}}$ is the estimate of $P_{\mathrm{i}} ; t_{(1-\gamma / 2),(\mathrm{n}-\mathrm{m})}$ is the t-distribution at the $(1-\gamma / 2) \times 100$ percent confidence level; $(n-m)$ is the degrees of freedom; $n$ is the number of observations; $m$ is the number of parameters estimated; and $s_{\mathrm{P}_{\mathrm{i}}}$ is the estimate of the variance of $P_{\mathrm{i}}$ which is calculated from the sum of squares of the error, ${s_{\mathrm{E}}}^{2}$, as follows

$$
s_{\mathrm{P}_{\mathrm{i}}}=\sqrt{\mathrm{C}_{\mathrm{ii}} s_{\mathrm{E}}{ }^{2}}
$$

In Eq. [24], $C_{\mathrm{ii}}$ is an element of the matrix $\left(\mathbf{J}^{\mathrm{T}} \mathbf{J}\right)^{-1}$ [i.e., inverse of the approximate Hessian, see appendix B in Ref. (15)]. The estimate of the variance in the error, $s_{\mathrm{E}}{ }^{2}$, is calcu- lated from the sum of squares of the residual errors (SSR) as follows

$$
S_{\mathrm{E}}^{2}=\frac{S S R}{n-m}=\frac{\sum_{\mathrm{j}=1}^{\mathrm{n}_{\mathrm{j}}}\left(E\left(t_{\mathrm{j}}\right)_{\mathrm{obs}}-E\left(t_{\mathrm{j}}\right)_{\mathrm{pred}}\right)^{2}}{n-m}
$$

Parameter estimation using high-rate simulated data.The use of high-rate (e.g., $30 \mathrm{~mA} / \mathrm{cm}^{2}$ ) discharge data for parameter estimation seems to offer several advantages. High-rate discharges occur over a relatively small time as opposed to low-rate discharges (e.g., about $1 \mathrm{~h}$ for a 30 $\mathrm{mA} / \mathrm{cm}^{2}$ discharge as opposed to approximately $50 \mathrm{~h}$ for a 1 $\mathrm{mA} / \mathrm{cm}^{2}$ discharge of a $\mathrm{Li} / \mathrm{SOCl}_{2}$ cell). This means less time in the lab and, perhaps, less computer time to simulate the discharge. Often, the shapes of voltage-time curves for high-rate discharges are much more curved than the relatively flat voltage-time curves for low-rate discharges thus offering more information for the parameter estimation.

Here, however, the use of high-rate data exhibited several disadvantages. First, the influence of species transport becomes important at the higher discharge rates. For example, at $100 \mathrm{~mA} / \mathrm{cm}^{2}$ the sensitivity coefficient, as calculated using Eq. [12], for the transference number is 0.3 , which is second only to the sensitivity coefficient of $\alpha_{a, 4}$, 0.53 . Due to the uncertainty in the transference number and the lack of data for the diffusion coefficient [see appendix A in Ref. (15)] it is best to stay clear of those operating regions where species transport is a controlling aspect of the cell discharge. Secondly, at high rates much interaction exists between the electrode kinetic parameters. This interaction can be seen in Fig. 4, which is a plot of the timedependent sensitivity coefficients [i.e., the elements of the Jacobian matrix, as shown in appendix B in Ref. (15)] for a $31 \mathrm{~mA} / \mathrm{cm}^{2}$ simulated discharge. These sensitivity coefficients are calculated using Eq. [12] except that the perturbation in each parameter, $\triangle P_{\mathrm{i}}$, is not scaled by $P^{*}{ }_{\mathrm{i}}$ as in $\mathrm{Eq}$. $[14]$ but is calculated as follows

$$
\triangle P_{\mathrm{i}}=P_{\mathrm{i}}-P_{\mathrm{i}}^{*_{\mathrm{i}}}
$$

Note that three of the five parameters, $\ln \left(\alpha^{\circ} i_{\mathrm{o}, 4, \mathrm{ref}}\right), \alpha_{\mathrm{a}, 1}$, and $\ln \left(i_{o, 1, \text { ref }}\right)$, influence the cell voltage in the same fashion.

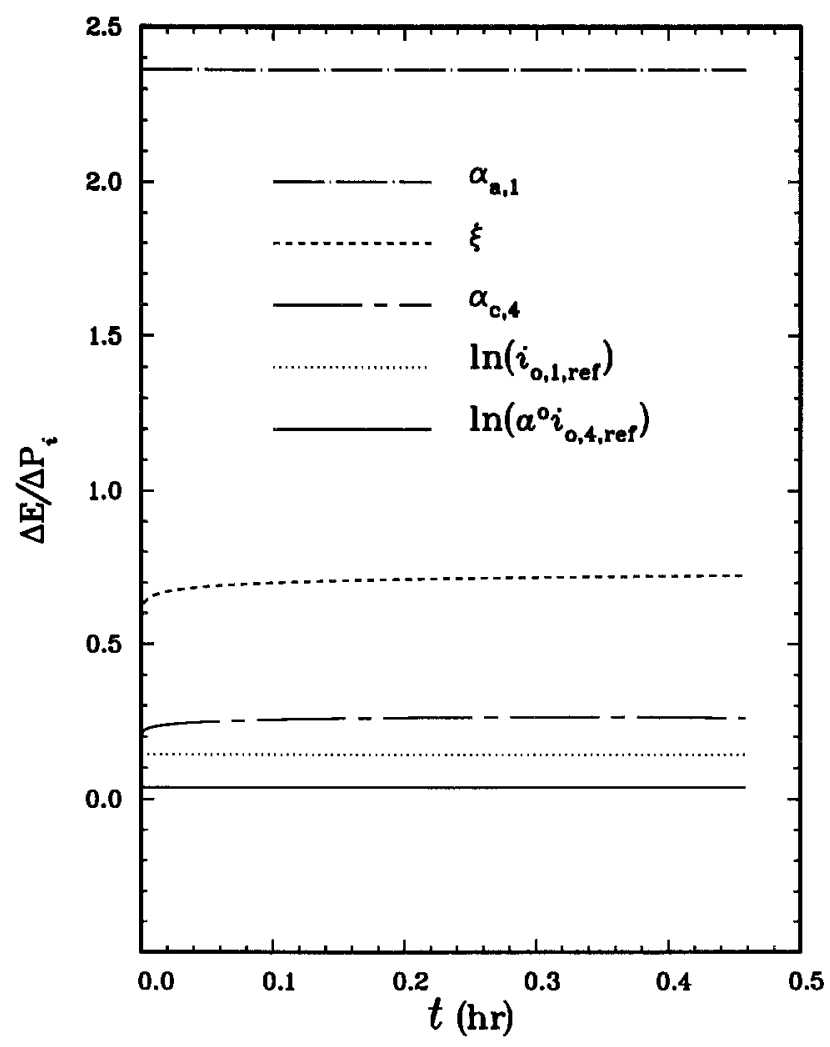

Fig. 4. Time-dependent sensitivity coefficients for a $31 \mathrm{~mA} / \mathrm{cm}^{2}$ simulated discharge evaluated at the exact values of the electrode kinetic parameters. Parallel lines indicate parameter interaction. 
This similar influence (i.e., interaction) is shown by the three straight parallel lines (14) in the figure. Thus, only one of these three parameters can be determined independently. Note also that the two lithium oxidation parameters cannot be individually obtained at high rates.

Another indication of this interaction is the condition number of the approximate Hessian (11) (see appendix B in Ref. 15). The condition number of a matrix is the ratio of its largest eigenvalue to its smallest eigenvalue. A matrix is called ill-conditioned when its condition number is large. The larger the condition number, the more substantial the change in the solution even with very small changes in the data. In essence, a large condition number here means that a unique set of electrode kinetic parameters is more difficult to find; many sets will reduce the objective function to nearly the same value. The condition number for the approximate Hessian here was on the order of $1 \times 10^{18}$. The reason for this ill-conditioning could be the fact that transport becomes more important at higher rates which serves to decrease the influence of changes in the electrode kinetic parameters on cell performance.

Though interaction between some of the parameters exists at high rates, several attractive features can be noted. If the lithium oxidation parameters, $i_{o, 1, \text { ref }}$ and $\alpha_{\mathrm{a}, 1}$, are known a priori via independent means, then the $\mathrm{SOCl}_{2}$ electrode kinetic parameters can be determined using high-rate data. This ability is shown in Table II where $\ln \left(\alpha^{\circ} i_{0,4, \mathrm{ref}}\right), \alpha_{c, 4}$, and $\xi$ are estimated from simulated $31 \mathrm{~mA} / \mathrm{cm}^{2}$ data with $0.5 \mathrm{mV}$ added random noise. This ability is important because the $\mathrm{SOCl}_{2}$ electrode kinetic parameters will probably change with discharge rate due to changes in the active surface area in the porous electrode as discharge proceeds. In addition, the sensitivity of the predicted cell voltage to changes in $\xi$ seems to be greater at high rates than at low rates thus enabling better estimates of $\xi$. This can be seen by comparing the sizes of the confidence intervals for $\xi$ here with those in the next section.

Parameter estimation using low-rate simulated data.Parameter estimation on low-rate data (e.g., $1 \mathrm{~mA} / \mathrm{cm}^{2}$ ) remedies some of the problems encountered with the high-rate data. The interaction between parameters is decreased. Figure 5 is a plot of the sensitivity coefficients $v$ s. time for the $1 \mathrm{~mA} / \mathrm{cm}^{2}$ simulated discharge. The curves have differing slopes and shapes, as opposed to those for the high-rate case as shown in Fig. 4, indicating that the various parameters affect cell voltage differently and hence can be determined independently. Note that these coefficients are calculated using the known values of the electrode kinetic parameters. Table III lists the condition numbers for the approximate Hessians for various combinations of the parameters; the various combinations are indicated by case. The condition numbers for cases $\mathrm{A}$ and $\mathrm{E}$ are low, suggesting that parameter estimations for either of these cases ought to be straightforward and the confidence intervals on the parameter estimates small (11)

Table II. Estimated values of the $\mathrm{SOCl}_{2}$ reduction electrode kinetic parameters using high rate $\left(31 \mathrm{~mA} / \mathrm{cm}^{2}\right)$ simulated data with added noise

\begin{tabular}{lll}
\hline Actual values*: & $\begin{array}{l}\alpha^{\circ} i_{\text {o, }, \text { ref }}=0.0441 \mathrm{~A} / \mathrm{cm}^{3} \\
\alpha_{\mathrm{c}, 4}=0.6846 \\
\xi=0.05\end{array}$ \\
\hline$Z(\mathrm{mV})$ & Starting values & $\begin{array}{l}\text { Estimated values } \\
(95 \% \text { confidence, } \gamma=0.05)\end{array}$ \\
\hline 0.5 & $\ln \left(a^{\circ} i_{0,4, \mathrm{ref}}\right)=-5.423$ & $-3.073 \pm 0.0609$ \\
& $\left(a^{\circ} i_{0,4, \mathrm{ref}}=0.00441\right)$ & $\left(0.0463_{-0.00274}^{+0.00291}\right)$ \\
& $\alpha_{\mathrm{c}, 4}=0.171$ & $0.681 \pm 0.0361$ \\
& $\stackrel{5}{=} 0.01$ & $0.0487 \pm 0.01356$ \\
\hline
\end{tabular}

*The lithium oxidation electro-kinetic parameters were held fixed here at the following values:
$i_{0,1}$ ref
\[ .58 \times 10^{-3} \] $\alpha_{\mathrm{a} .1}=0.18$
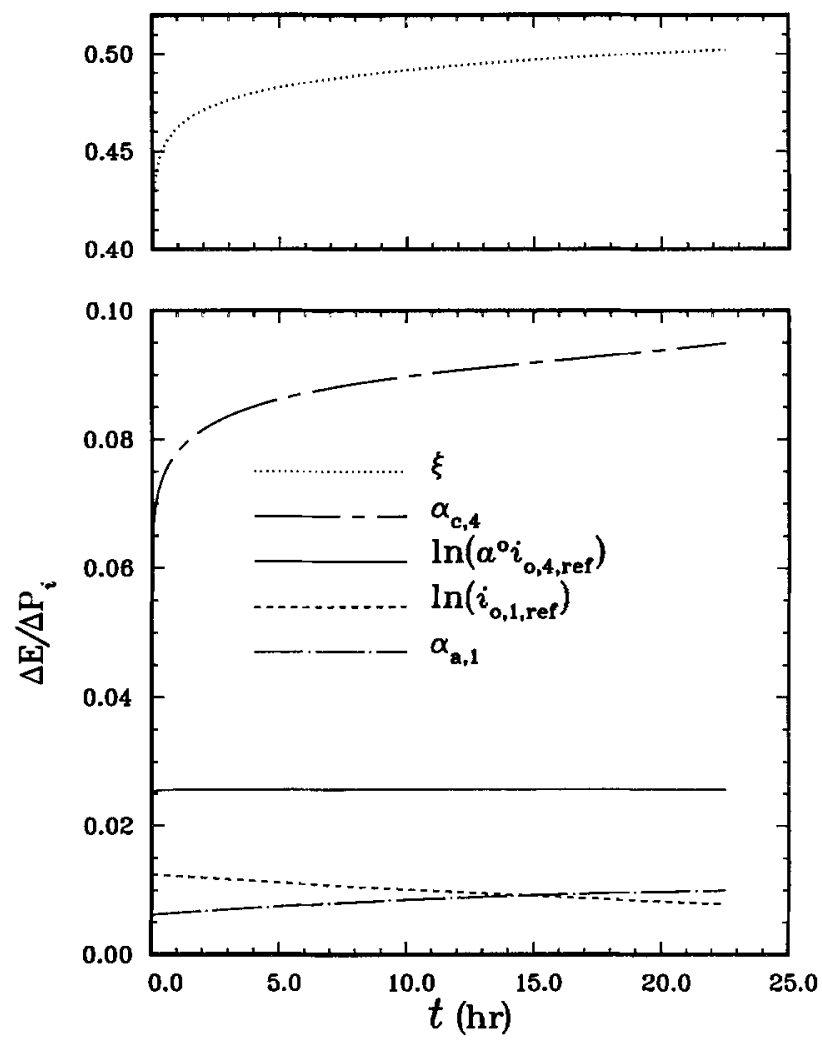

Fig. 5. Time-dependent sensitivity coefficients for a $1 \mathrm{~mA} / \mathrm{cm}^{2}$ simulated discharge evaluated at the exact values of the electrode kinetic parameters.

Here, the term straightforward parameter estimation means that the search proceeds to the solution given a variety of initial guesses that can be "far" from the correct solution. More difficult parameter estimation runs involve multiple initial guesses in order to make sure the estimates obtained with a particular initial guess are not those at a local minimum. A comparison of cases $A$ and $B$ shows that estimates for all three $\mathrm{SOCl}_{2}$ electrode kinetic parameters will be more difficult to obtain than estimates for $\ln$ $\left(a^{\circ} i_{0,4, \text { ref }}\right)$ and $\alpha_{c, 4}$ alone. Case $G$ shows that the eightparameter problem is extremely ill-conditioned, meaning much interaction between parameters and very large confidence intervals on the parameter estimates. Therefore, $q_{+, 1}, q_{+, 4}$, and $q_{0,4}$ are omitted from the following parameter estimation work and are set to their stoichiometric values as in Table I.

The simulated data for the $1 \mathrm{~mA} / \mathrm{cm}^{2}$ discharge investigated here, with added noise, are shown in Fig. 6. The model inputs are listed in Table I. The data in Fig. 6 spans approximately $50 \%$ of the discharge. Although predicted discharge times are much longer for low-rate than for highrate cases, the solution times for low-rate cases may actually be smaller than those for high-rate cases. Solution times depend upon the number of spatial nodes, the size of the time steps, and the number of iterations (at each time) to converge upon the solution. At low rates, changes in the dependent variables (electrolyte concentration, current,

Table III. Condition numbers for the approximate Hessians of the least squares objective function for the $1 \mathrm{~mA} / \mathrm{cm}^{2}$ simulated discharge. Large condition numbers indicate parameter interaction

\begin{tabular}{|c|c|c|}
\hline Case & Approximate Hessian of & $\begin{array}{c}\text { Condition } \\
\text { number }\end{array}$ \\
\hline \multirow{6}{*}{$\begin{array}{l}A \\
B \\
C \\
D \\
\text { E } \\
F \\
G\end{array}$} & \multirow{6}{*}{ 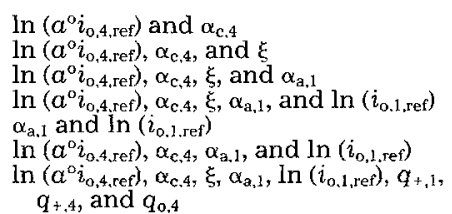 } & $5.62 \times 10^{2}$ \\
\hline & & $1.18 \times 10^{5}$ \\
\hline & & $\begin{array}{l}1.14 \times 10^{6} \\
6.16 \times 10^{7}\end{array}$ \\
\hline & & $4.30 \times 10^{1}$ \\
\hline & & $1.03 \times 10^{6}$ \\
\hline & & $2.45 \times 10^{12}$ \\
\hline
\end{tabular}




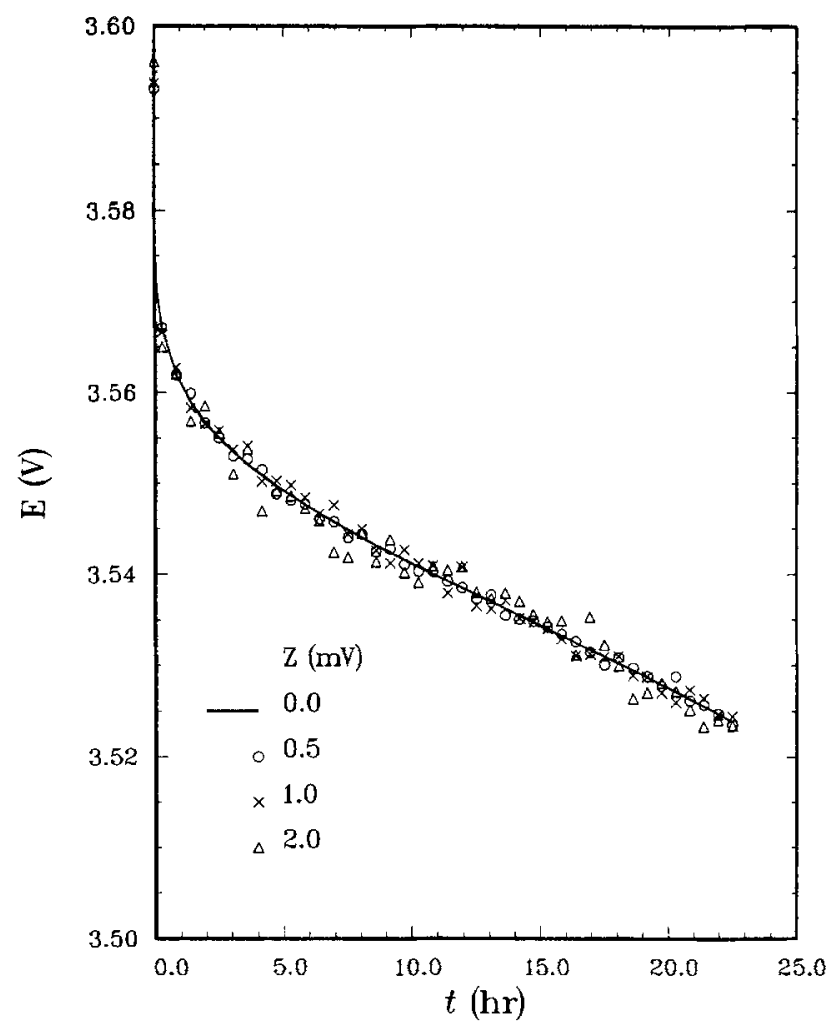

Fig. 6. A simulated $1 \mathrm{~mA} / \mathrm{cm}^{2}$ discharge of a $\mathrm{Li} / \mathrm{SOCl}_{2}$ cell with three levels of added random noise.

and potential) in space and time occur much less rapidly than at high rates. Therefore, fewer node points and larger time steps can be used at low rate than at high rate to maintain three-digit accuracy. For example, 81 nodes and a maximum time step of $37.5 \mathrm{~s}$ were used to maintain threedigit accuracy for the $31 \mathrm{~mA} / \mathrm{cm}^{2}$ discharge results reported earlier. Here, for the $1 \mathrm{~mA} / \mathrm{cm}^{2}$ discharge, 21 nodes and a maximum time step of 2000 s were sufficient. This result eliminates the advantages of using high-rate data to reduce solution time; the only disadvantage to using lowrate data is the length of time it takes to collect the experimental data.

The results of the parameter estimation runs are shown in Table IV-VII. As expected, the runs for cases A and $\mathrm{E}$ were straightforward with narrow confidence intervals for the parameter estimates. As shown in Table IV and V, the initial guesses are at different extremes and up to two orders of magnitude away from the true solution. Notice how

Table IV. Estimated values of the lithium oxidation electrode kinetic parameters using simulated $1 \mathrm{~mA} / \mathrm{cm}^{2}$ data with added noise

\begin{tabular}{|c|c|c|}
\hline Actual values: & $\begin{array}{l}i_{\mathrm{o}, 1, \mathrm{ref}}=0.002 \mathrm{~A} / \mathrm{cm}^{2} \\
\alpha_{\mathrm{a}, 1}=0.5\end{array}$ & (Case E) \\
\hline$Z(\mathrm{mV})$ & Starting values & $\begin{array}{l}\text { Estimated values } \\
(95 \% \text { confidence, } \gamma=0.05)\end{array}$ \\
\hline \multirow[t]{3}{*}{0.5} & $\ln \left(i_{\text {o.l.ref }}\right)=-8.517$ & $-6.223 \pm 0.062$ \\
\hline & $\left(i_{\mathrm{o}, 1, \mathrm{ref}}=2.0 \times 10^{-4}\right)$ & $\left(\begin{array}{ll}0.00198 & +1.27 \times 10^{-4} \\
& -1.19 \times 10^{-4}\end{array}\right)$ \\
\hline & $\alpha_{a, 1}=0.15$ & $0.508 \pm 0.072$ \\
\hline \multirow[t]{3}{*}{1.0} & $\ln \left(i_{o, 1, \mathrm{ref}}\right)=-8.517$ & $-6.144 \pm 0.105$ \\
\hline & $\left(i_{0,1,5 e f}=2.0 \times 10^{-4}\right)$ & $\left(\begin{array}{ll}0.002145 & +2.375 \times 10^{-4} \\
& -2.139 \times 10^{-4}\end{array}\right)$ \\
\hline & $\alpha_{a, 1}=0.15$ & $0.432 \pm 0.126$ \\
\hline \multirow[t]{3}{*}{1.0} & $\ln \left(i_{\mathrm{o}, 1, \mathrm{ref}}\right)=-10.82$ & $-6.144 \pm 0.100$ \\
\hline & $\left(i_{\mathrm{o} .1, \mathrm{ref}}=2.0 \times 10^{-5}\right)$ & $\left(\begin{array}{ll}0.002146 & +2.256 \times 10^{-4} \\
-2.042 \times 10^{-4}\end{array}\right)$ \\
\hline & $\alpha_{a, 1}=0.85$ & $0.432 \pm 0.118$ \\
\hline \multirow[t]{3}{*}{2.0} & $\ln \left(i_{o, 1, \text { ref }}\right)=-8,517$ & $-6.263 \pm 0.211$ \\
\hline & $\left(i_{\mathrm{o}, 1, \mathrm{ref}}=2.0 \times 10^{-4}\right)$ & $\left(\begin{array}{ll}0.0019066^{+4.476 \times 10^{-4}} \\
-3.625 \times 10^{-4}\end{array}\right)$ \\
\hline & $\alpha_{\mathrm{a} .1}=0.15$ & $0.5337 \pm 0.248$ \\
\hline
\end{tabular}

Table V. Estimated values of the exchange current density and transfer coefficient of the $\mathrm{SOCl}_{2}$ reduction reaction using simulated $1 \mathrm{~mA} / \mathrm{cm}^{2}$ data with added noise

\begin{tabular}{|c|c|c|}
\hline Actual values: & $\begin{array}{l}a^{\mathrm{o}} i_{0.4, \mathrm{ref}}=0.005 \mathrm{~A} / \mathrm{cm}^{3} \\
\alpha_{\mathrm{c} .4}=1.0\end{array}$ & (Case A) \\
\hline$Z(\mathrm{mV})$ & Starting values & $\begin{array}{l}\text { Estimated values } \\
(95 \% \text { confidence, } \gamma=0.05)\end{array}$ \\
\hline \multirow[t]{2}{*}{0.5} & $\begin{array}{c}\ln \left(a^{\mathrm{o}} \hat{i}_{0.4 . \mathrm{ref}}\right)=-2.996 \\
\left(a^{\mathrm{o}} i_{0.4 \text {. ref }}=0.05\right)\end{array}$ & $\begin{array}{l}-5.293 \pm 0.0732 \\
\left(\begin{array}{c}0.00503 \\
+3.82 \times 10^{-4} \\
-3.55 \times 10^{-4}\end{array}\right)\end{array}$ \\
\hline & $\alpha_{c, 4}=0.25$ & $0.9981 \pm 0.0212$ \\
\hline \multirow[t]{2}{*}{0.5} & $\begin{array}{l}\ln \left(a^{0} i_{0,4 \text {, ref }}\right)=-9.903 \\
\quad\left(a^{0} i_{0,4 \text {, ref }}=5.0 \times 10^{-5}\right)\end{array}$ & $\begin{array}{l}-5.293 \pm 0.0732 \\
\left(\begin{array}{c}0.00503 \\
+3.82 \times 10^{-4} \\
-3.55 \times 10^{-4}\end{array}\right)\end{array}$ \\
\hline & $\alpha_{c, 4}=1.75$ & $0.9981 \pm 0.0212$ \\
\hline \multirow[t]{2}{*}{1.0} & $\begin{array}{c}\ln \left(a^{\mathrm{o}} i_{\alpha, 4, \mathrm{ref}}\right)=-0.6931 \\
\left(a^{\mathrm{o}} i_{0,4, \mathrm{ref}}=0.5\right)\end{array}$ & $\begin{array}{ll}-5.239 \pm 0.123 \\
\left(\begin{array}{ll}0.0053 & +6.948 \times 10^{-4} \\
& -6.144 \times 10^{-4}\end{array}\right)\end{array}$ \\
\hline & $\alpha_{\mathrm{c}, 4}=0.25$ & $0.9842 \pm 0.0357$ \\
\hline 2.0 & $\begin{aligned} \ln \left(\alpha^{\mathrm{o}} i_{0.4 \text {.ref }}\right) & =-9.903 \\
\left(\alpha^{\mathrm{o}} i_{0.4 . \mathrm{ref}}\right. & \left.=5.0 \times 10^{-5}\right)\end{aligned}$ & $\begin{array}{c}-5.212 \pm 0.234 \\
\left(\begin{array}{c}0.00545 \\
+0.00144 \\
-0.00114\end{array}\right)\end{array}$ \\
\hline & $\alpha_{\mathcal{c}, 4}=1.75$ & $0.9727 \pm 0.0677$ \\
\hline
\end{tabular}

Table VI. Estimated values of the $\mathrm{SOCl}_{2}$ reduction electrode kinetic parameters using simulated $1 \mathrm{~mA} / \mathrm{cm}^{2}$ data with added noise

\begin{tabular}{|c|c|c|}
\hline Actual values: & $\begin{array}{l}a^{0} i_{\mathrm{o} .4 . \text { ref }}=0.005 \mathrm{~A} / \mathrm{cm}^{3} \\
\alpha_{\text {c.4 }}=1.0 \\
\xi=0.05\end{array}$ & (Case B) \\
\hline$Z(\mathrm{mV})$ & Starting values & $\begin{array}{l}\text { Estimated values } \\
(95 \% \text { confidence, } \gamma=0.05)\end{array}$ \\
\hline \multirow[t]{2}{*}{0.5} & $\begin{aligned} \ln \left(a^{\circ} i_{0,4, \mathrm{re}}\right) & =-7.601 \\
\left(a^{\circ} i_{0,4 \text {, ref }}\right. & \left.=5.0 \times 10^{-4}\right)\end{aligned}$ & $\begin{array}{c}-5.289 \pm 0.129 \\
\left(\begin{array}{rl}0.00505 & +6.95 \times 10^{-4} \\
& -6.11 \times 10^{-4}\end{array}\right)\end{array}$ \\
\hline & $\begin{array}{l}\alpha_{\mathrm{c} .4}=0.25 \\
\xi=0.01\end{array}$ & $\begin{array}{l}1.001 \pm 0.075 \\
0.0494 \pm 0.0184\end{array}$ \\
\hline \multirow[t]{2}{*}{1.0} & $\begin{aligned} \ln \left(a^{0} i_{\text {o. } 4 \text { ref }}\right) & =-9.903 \\
\left(a^{0} i_{\text {o. } 4 \text {, ref }}\right. & \left.=5.0 \times 10^{-5}\right)\end{aligned}$ & $\begin{array}{l}-5.257 \pm 0.189 \\
\left(\begin{array}{c}0.00521 \\
+1.085 \times 10^{-3} \\
-8.98 \times 10^{-4}\end{array}\right)\end{array}$ \\
\hline & $\begin{array}{l}\alpha_{c, 4}=1.75 \\
\xi=0.01\end{array}$ & $\begin{array}{l}0.9707 \pm 0.1238 \\
0.0535 \pm 0.0313\end{array}$ \\
\hline
\end{tabular}

the confidence intervals increase as the noise level in creases, which is to be expected. Case E may be useful when estimates of the $\mathrm{SOCl}_{2}$ electrode kinetic parameters have been obtained independently. Similarly, case A may be needed when estimates of the lithium oxidation electrode kinetic parameters are available and an estimate of $\xi$ is known from independent studies. Table VI lists parameter estimation runs for case $\mathrm{B}$, all three $\mathrm{SOCl}_{2}$ reduction electrode kinetic parameters. This case, as shown in the previous section, can be used to determine both low-rate and high-rate values of $\alpha^{\circ} i_{0,4, \text { ref }}, \alpha_{c, 4}$, and $\xi$ when estimates of $\alpha_{\mathrm{a}, 1}$ and $\ln \left(i_{0,1, \mathrm{ref}}\right)$ are known. Notice the increase in the size of the confidence intervals from Table V to Table VI. The estimation of the additional parameter, $\xi$, adds greater uncertainty to the parameter estimates, as expected. Also, judging from the large increase in condition number from case A to case B in Table III, some interaction between these parameters is evident.

Table VII lists parameter estimation runs for case D. The ability to estimate all five electrode kinetic parameters at once, as in case D, is attractive. Simultaneous estimation of all parameters in the model usually provides parameter estimates possessing superior predictive capability. Often, independently determined parameter estimates do not predict the behavior of the entire unit very well. For example, independent estimates of the lithium oxidation parameters and $\mathrm{SOCl}_{2}$ reduction parameters may not be useful for predicting the behavior of the $\mathrm{Li} / \mathrm{SOCl}_{2}$ cell. These independent estimates might be obtained from rotating disk electrode experiments and a corresponding mathe- 
Table VII. Estimated values of all five electrode kinetic parameters describing the $\mathrm{Li} / \mathrm{SOCl}_{2}$ cell using simulated $1 \mathrm{~mA} / \mathrm{cm}^{2}$ data with added noise

$\begin{array}{lll}\text { Actual values: } & a^{\circ} i_{\text {o.4. ref }}=0.005 \mathrm{~A} / \mathrm{cm}^{3} \quad \text { (Case D) } \\ & \alpha_{\mathrm{c}, 4}=1.0 \\ & \xi=0.05 \\ & i_{0.1 . \mathrm{ref}}=0.002 \mathrm{~A} / \mathrm{cm}^{2} \\ & \alpha_{\mathrm{a}, 1}=0.5\end{array}$

\begin{tabular}{|c|c|c|}
\hline $\mathrm{Z}(\mathrm{mV})$ & Starting values & $\begin{array}{l}\text { Estimated values } \\
(95 \% \text { confidence, } \gamma=0.05)\end{array}$ \\
\hline 0.0 & $\begin{array}{l}\ln \left(a^{\mathrm{o}} i_{\text {o.4.ref }}\right)=-7.601 \\
\quad\left(a^{\mathrm{o}} i_{\text {o.4., ef }}=\left(5.0 \times 10^{-4}\right)\right. \\
a_{\mathrm{c} .4}=0.5 \\
\xi=0.025 \\
\ln \left(i_{0,1, \mathrm{ref}}\right)=-8.517 \\
\quad\left(i_{0,1, \mathrm{erf}}=2.0 \times 10^{-4}\right) \\
\alpha_{\mathrm{a}, 1}=0.25 \\
\quad \mathrm{SSR}=1.0 \times 10^{-18}\end{array}$ & $\begin{array}{l}-5.298 \\
\left(5.0 \times 10^{-3}\right) \\
1.00 \\
0.05 \\
-6.215 \\
\left(2.0 \times 10^{-3}\right) \\
0.5\end{array}$ \\
\hline \multirow[t]{3}{*}{0.5} & $\begin{aligned} \ln \left(a^{0} i_{0,4, \text { ref }}\right) & =-7.601 \\
\left(a^{0} i_{0,4, \text { ref }}\right. & \left.=5.0 \times 10^{-4}\right)\end{aligned}$ & $\begin{array}{l}-5.031 \pm 2.078 \\
\left(\begin{array}{ll}0.00653 & +0.0457 \\
-0.00571\end{array}\right)\end{array}$ \\
\hline & $\begin{array}{l}\alpha_{\mathrm{c.4}}=0.5 \\
\xi=0.025 \\
\ln \left(i_{\text {o.1.ref }}\right)=-8.517 \\
\quad\left(i_{\text {o.1.ref }}=2.0 \times 10^{-4}\right)\end{array}$ & $\begin{array}{l}1.00 \pm 0.253 \\
0.0656 \pm 0.0678 \\
-6.523 \pm 1.292 \\
\left(\begin{array}{r}0.00147 \\
+0.00388 \\
-0.00107\end{array}\right)\end{array}$ \\
\hline & $\begin{array}{l}\alpha_{a .1}=0.25 \\
\quad \operatorname{SSR}=1.067 \times 10^{-5}\end{array}$ & $0.374 \pm 1.80$ \\
\hline
\end{tabular}

matical model. In Table VII, note that for the data with added $0.5 \mathrm{mV}$ noise, the confidence intervals on certain parameter estimates are unacceptably large. This uncertainty in the predictions is due to parameter interaction (note the relatively large condition number in Table III) even at this low rate of discharge. The five parameters can be obtained with no noise, as shown in Table VII, but it is unrealistic to expect exact measurements and the model to be an exact description of the physical system. It may be useful to obtain all five parameters simultaneously, even though the confidence intervals are large, because the estimates should still provide an excellent fit of the model predictions to the experimental data (notice the small SSR in Table VII). The parameter estimation runs for cases B and $\mathrm{D}$ were not straightforward. Certain initial guesses of the parameters detoured the search algorithm to local minimums. For example, for the case D runs, the initial guesses of the exchange current densities needed to be within an order of magnitude and the transfer coefficient guesses needed to be within about half of their true value in order to reach convergence. The algorithm could not escape these local minimums within a reasonable number of iterations (e.g., 60 iterations).

An alternative to predicting all five parameters simultaneously would be to obtain estimates for some of the parameters independently (for example, the lithium oxidation parameters), and then use these estimates in the cell model to obtain the remaining parameters (the $\mathrm{SOCl}_{2}$ reduction parameters), using data from the entire cell. In addition, separate data for each electrode in the $\mathrm{Li} / \mathrm{SOCl}_{2}$ cell could be obtained. For example, the lithium electrode potential could be measured in a $\mathrm{Li} / \mathrm{SOCl}_{2}$ cell by placing a reference electrode near the surface of the lithium electrode. The lithium electrode would be the working electrode, a second lithium electrode (with high impedance) placed near the surface of the working electrode would act as the reference electrode, and the porous carbon cathode would be the counterelectrode. The potential of the lithium electrode, as it changes with time, could then be measured relative to the reference electrode. Predictions of the $\mathrm{Li}$ electrode potential could be obtained from a model of the working electrode/reference electrode system, consisting of equations presented earlier for the entire $\mathrm{Li} / \mathrm{SOCl}_{2}$ cell. These predictions could then be compared with the experimental values to obtain estimates of the electrode kinetic parameters of the lithium electrode.

Parameter estimation using available experimental data.-The analyses using simulated data in the previous sections have shown the need to collect low-rate data from a well defined experimental cell. Unfortunately, no such experimental data is currently available. Various experimental voltage-time curves have been reported (16-19), but it is difficult to use this data due to the lack of cell specifications given (e.g., porous electrode porosity and thickness, initial electrolyte concentration, temperatures, and separator porosity and thickness). In addition, large differences exist in the experimental data which can be attributed to the different electrode materials, initial electrolyte concentrations, operating conditions, and cell dimensions used.

Using data from Klinedinst (20), for a $31 \mathrm{~mA} / \mathrm{cm}^{2}$ discharge of an experimental cell (4), estimates of the $\mathrm{SOCl}_{2}$ reduction electrode kinetic parameters were obtained. The lithium oxidation electrode kinetic parameters were arbitrarily set to the values listed in Table I of Ref. $3\left(i_{\text {ol.ref }}\right.$ $=0.5 \mathrm{~mA} / \mathrm{cm}^{2}$ and $\alpha_{a, 1}=0.25$ ). These values are well within ranges commonly used in the literature for electrochemical reactions. Initially, a by-hand trial and error search was conducted to find electrode kinetic parameters giving model predictions close to the experimental results. It was hoped that this search would provide initial guesses in the vicinity of their actual values to aid in the parameter estimation. Two sets of initial guesses were tried, as shown in Table VIII as Run no. 1 and Run no. 2, and the same final parameter values were obtained to within the confidence limits shown. The values are listed in Table VIII and the predicted voltage curve, obtained using the estimates from Run no. 1, is superimposed on the experimental data in Fig. 7. Note that the confidence intervals for $\boldsymbol{\alpha}^{\circ} i_{\text {o.4,ref }}$ and $\xi$ in Run no. 1 and Run no. 2 are large relative to the estimated values of the parameters. To reduce the uncertainty in the estimate of $a^{\circ} i_{0,4 \mathrm{ref}}, \xi$ was set to a value of 0.02 (a value between the estimates of $\xi$ in Run no. 1 and Run no. 2 ) for Run no. 3. This procedure (estimating all three $\mathrm{SOCl}_{2}$ electrode kinetic parameters, setting $\xi$ to an average value, and then estimating $a^{\mathrm{o}} i_{0,4 \text {, ef }}$ and $\alpha_{c, 4}$ ) gives estimates of $a^{0} i_{0,4, \text { ref }}$ and $\alpha_{c, 4}$ with reasonable confidence intervals and an estimate of $\xi$ in the vicinity of its best value.

Notice in Fig. 7 that the first experimental data point used occurs some time after the beginning of the discharge. This is because the beginning behaviors of experimental discharge curves are very different. Some exhibit a very sudden and large initial decrease followed by a time of voltage recovery, known as the voltage-delay phenomena. Others show a steady decrease, with an initial large decrease, as the model predictions do. The voltage-delay phenomenon in $\mathrm{Li} / \mathrm{SOCl}_{2}$ cells has been studied by Dey (21) and has been associated with the $\mathrm{LiCl}$ film. Slow voltage recovery is associated with slow mechanical disruption of the film. The model does not account for this voltage-delay phenomena and therefore initial experimental data were excluded from the parameter estimation.

Table VIII. Estimated values of the $\mathrm{SOCl}_{2}$ reduction electrode kinetic parameters of the $\mathrm{Li} / \mathrm{SOCl}_{2}$ cell using available experimental data at $31 \mathrm{~mA} / \mathrm{cm}^{2}$

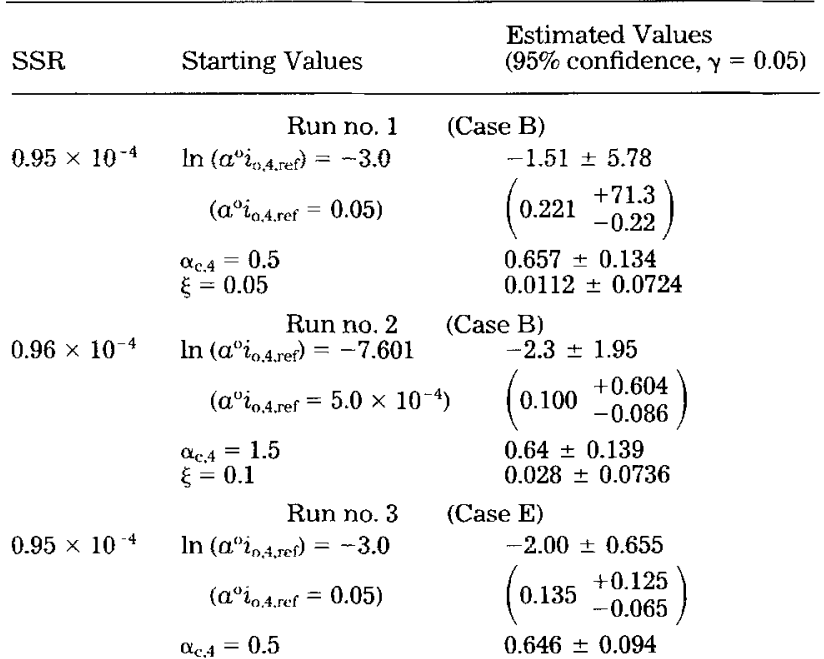




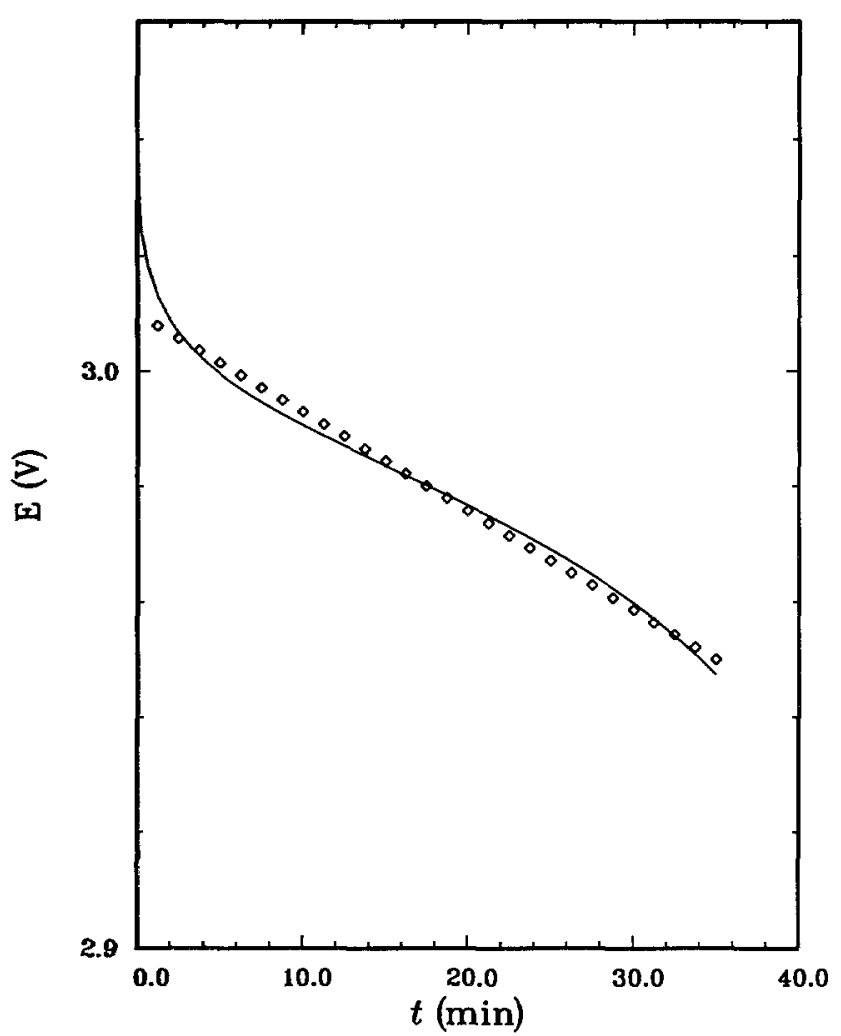

Fig. 7. A comparison of model predictions to experimental data at $31 \mathrm{~mA} / \mathrm{cm}^{2}$. Electrode kinetic parameters are as shown in Table VIII, Run no. 1.

\section{Conclusions}

The sensitivity analysis and parameter estimation performed here for the model presented by Evans et al. (3) yield several conclusions. The test cell of Klinedinst and Domeniconi (4) offers a constant temperature environment, a single cell (as opposed to a stack), elimination of film and reservoir regions, and well-defined thicknesses of the cell components. Low-rate data should be used to obtain estimates of the electrode kinetic parameters so that interaction between parameters is small. Low-rate data is just as efficient to use in the parameter estimation procedure as is high-rate data because the number of nodes can be decreased and the time step increased so that the solution times are comparable. Also, at low rates the effects of species transport are minimal. Once estimates of the lithium oxidation parameters are available, the electrode kinetic parameters describing the $\mathrm{SOCl}_{2}$ reduction on the porous carbon electrode can be determined even for high discharge rates. These parameters will change with electrolyte composition, type of carbon used for the electrode, and temperature.

Manuscript submitted Sept. 23, 1988; revised manuscript received Feb. 22, 1989.

Texas A\&M University assisted in meeting the publication costs of this article.

\section{LIST OF SYMBOLS}

a specific electroactive surface area of the porous electrode, $\mathrm{m}^{-1}$

$a^{0} \quad$ initial value of $a, \mathrm{~m}^{-1}$

$c_{\mathrm{i}} \quad$ concentration of species $\mathrm{i}, \mathrm{mol} / \mathrm{m}^{3}$

$c_{\text {init }}$ initial concentration of electrolyte, $\mathrm{mol} / \mathrm{m}^{3}$

$c_{\text {i.ref }}$ reference concentration of species $\mathrm{i}, \mathrm{mol} / \mathrm{m}^{3}$

$C_{\mathrm{ii}}$ diagonal element of approximate Hessian

$D$ diffusion coefficient of the binary electrolyte, $\mathrm{m}^{2} / \mathrm{s}$ $E$ cell voltage, $\mathrm{V}$

F Faraday's constant, $96,487 \mathrm{C} / \mathrm{mol}$ of electrons

$i_{\mathrm{k}} \quad$ current density due to electrochemical reaction $\mathrm{k}$, $\mathrm{A} / \mathrm{m}^{2}$

$i_{\mathrm{n}} \quad$ discharge current density, $\mathrm{A} / \mathrm{m}^{2}$

$i_{\text {o,k.ref }}$ exchange current density of electrochemical reaction $\mathrm{k}$ at $c_{\text {ref }}, \mathrm{A} / \mathrm{m}^{2}$ $j \quad$ current transferred between phases, $\mathrm{A} / \mathrm{m}^{3}$

$n$ number of data points

$n_{\mathrm{k}} \quad$ number of electrons transferred in the electrochemical reaction $\mathrm{k}$

$m$ number of parameters

$p_{i, k} \quad$ anodic reaction order of species $\mathrm{i}$ in reaction $\mathrm{k}$

$P_{\mathrm{i}} \quad$ parameter $\mathrm{i}$

$P^{*}{ }_{i} \quad$ reference value of parameter $i$

$\hat{P}_{j} \quad$ estimate of $P$

$q_{i, k} \quad$ cathodic reaction order of species $i$ in reaction $\mathrm{k}$

$R \quad$ universal gas law constant, $8.314 \mathrm{~J} / \mathrm{mol}-\mathrm{K}$

$s_{\mathrm{E}} \quad$ estimate of the variance of the residual error

$s_{\mathrm{P}_{i}} \quad$ estimate of the variance in the estimate of $P_{\mathrm{i}}$

$S_{1} \quad$ thickness of region $l, m$

$S C_{i} \quad$ sensitivity coefficient for parameter i

SSR sum of squares of the residual error

$T$ cell temperature, $\mathrm{K}$

$t_{\mathrm{j}} \quad$ time $j$, sec

$\triangle t_{\text {max }} \quad$ maximum time step, sec

$t_{\mathrm{i}}$ transference number of species $\mathrm{i}$

$U_{\mathrm{k}, \text { ref }}$ open-circuit potential of reaction $\mathrm{k}$ based on the reference concentrations, $\mathrm{V}$

$Z$ average level of noise, $V$

Greek Symbols

$\alpha_{a, k} \quad$ anodic transfer coefficient for reaction $\mathrm{k}$

$\alpha_{c, k} \quad$ eathodic transfer coefficient for reaction $k$

$\beta_{5} \quad$ transport parameter, $\mathrm{K}$

$\beta_{6} \quad$ transport parameter, $\mathrm{cm}^{2} / \mathrm{s}$

$\gamma \quad$ a fraction of the normal distribution

$\epsilon$ porosity of porous material

$\epsilon^{\circ} \quad$ initial porosity of the porous electrode

$\eta_{\mathrm{k}} \quad$ overpotential for reaction $\mathrm{k}$ at electrode surface $\left(\Phi_{\mathrm{s}}-\Phi_{\mathrm{o}}-U_{\mathrm{k}, \mathrm{ref}}\right), \mathrm{V}$

$\xi \quad$ morphology parameter

$\Phi$ solution potential, V

$\Phi_{\circ} \quad$ solution potential at electrode surface, $V$

$\Phi_{\mathrm{s}} \quad$ electrode potential, $\mathrm{V}$

$\Phi_{1} \quad$ potential of the solid phase, $\mathrm{V}$

$\Phi_{2} \quad$ solution potential V

$\phi \quad$ normally distributed random number

\section{REFERENCES}

1. D. H. Johnson, A. D. Ayers, R. L. Zupancic, V. S. Alberto, and J. C. Bailey, J. Power Sources, 12, 61 (1984).

2. S. Surampudi, G. Halpert, and I. Stein, JPL publication 86-15 (June 1986).

3. T. I. Evans, T. V. Nguyen, and R. E. White, This Journal, 136, 328 (1989).

4. K. A. Klinedinst and M. J. Domeniconi, ibid., 127, 539 (1980).

5. J. R. Driscoll, G. L. Holleck, and D. E. Toland, Proceedings of the 27th Power Sources Symposium, 28 (1976).

6. H. Gu, T. V. Nguyen, and R. E. White, This Journal, 134, 2953 (1987).

7. R. E. White, S. E. Lorimer, and R. Darby, ibid., 130, $1123(1983)$

8. J. S. Dunning, Ph.D. Dissertation, University of California, Los Angeles, CA (1971).

9. J. S. Dunning, D. N. Bennion, and J. Newman, This Journal, 120, 906 (1973).

10. J.S. Newman, "Electrochemical Systems," Prentice Hall, Inc., Englewood Cliffs, NJ (1973).

11. P. E. Gill, W. Murray, and M. H. Wright, "Practical Optimization," Academic Press, New York (1981).

12. T. V. Nguyen, Ph.D. Dissertation, Texas A\&M University, College Station, TX (1988).

13. "IMSL User's Manual," Edition 9.2, International Mathematical and Statistical Libraries, Inc. (1984).

14. B. Ostle and R. W. Mensing, "Statistics in Research," The Iowa State University Press, Ames, IA (1975).

15. T. I. Evans, Ph.D. Dissertation, Texas A\&M University, College Station, TX (1988).

16. J. J. Auborn, K. W. French, S. I. Lieberman, V. K. Shah, and A. Heller, This Journal, 120, 1613 (1973).

17. W. K. Behl, J. A. Christopulos, M. Ramirez, and S. Gilman, ibid., 1619 (1973).

18. K. M. Abraham, L. Pitts, and W. P. Kilroy, ibid., 132, 2301 (1985).

19. A. N. Dey, ibid., 126, 2052 (1979).

20. K. A. Klinedinst, ibid., 132, 2044 (1985).

21. A. N. Dey, Electrochim. Acta., 21, 377 (1976). 